\title{
OS STANDARDS PROBATÓRIOS COMO MÉTRICA DA VERDADE: EM BUSCA DE PARÂMETROS OBJETIVOS PARA A RACIONALIZAÇÃO DAS DECISÕES SOBRE OS FATOS*
}

\author{
Marcella Alves Mascarenhas Nardelli ${ }^{* *}$ \\ Fabiana Alves Mascarenhas**:*
}

\section{Resumen}

En este artículo se pretende analizar la búsqueda de la verdad como uno de los principales objetivos del proceso judicial, desde la concepción de Michele Taruffo. Por lo tanto, un enfoque interesante es el del reconocimiento de que el procedimiento de verificación de los hechos debe guiarse por nociones epistemológicas fundamentales para establecer

Recibido: marzo 28 de 2016 - Aprobado: julio 13 de 2016.

* El artíclulo es inedito y no hay sido presentado en cualquier congreso o ponencia.

Para citar el artículo: MASCARENHAS NARDELLI, Marcella y ALVES MASCARENHAS, Fabiana. Os standards probatórios como métrica da verdade: em busca de parâmetros objetivos para a racionalização das decisões sobre os fatos. Revista del Instituto Colombiano de Derecho Procesal. No. 44, julio- diciembre. 2016. Bogotá: Instituto Colombiano de Derecho Procesal. pp. 45- 66.

* Professora Assistente de Direito Processual Penal na Universidade Federal de Juiz de Fora - UFJF (Juiz de Fora, Brasil). Professora do Curso de Especializaçãoem Ciências Penais da Universidade Federal de Juiz de Fora - UFJF. Mestre em Políticas Públicas e Processo pela Faculdade de Direito de Campos (Campos dos Goytacazes, Brasil). Doutoranda em Direito Processual pela Universidade do Estado do Rio de Janeiro - UERJ (Rio de Janeiro, Brasil).

***: Professora de Direito Processual na Universidade Veiga de Almeida - UVA (Rio de Janeiro, Brasil). Mestre e Doutoranda em Sociologia e Direito pela Universidade Federal Fluminense -UFF (Niterói, Brasil). Mediadora Judicial do Tribunal de Justiça do Estado do Rio de Janeiro - TJ/RJ (Brasil). Pesquisadora do Laboratório Fluminense de Estudos Processuais da Universidade Federal Fluminense - LAFEP/UFF. Bolsista CAPES. 
Os standards probatórios como métrica da verdade: em busca de parâmetros objetivos

el mejor modo de aproximarse a la verdad. En este contexto, se puede concluir que los estándares de prueba sólo cumplen con el propósito de determinar si es posible considerar las hipótesis fácticas probadas si son elaborados de una manera objetiva y racional, así como preconiza Larry Laudan. Las concepciones de Taruffo acerca de la verdad en el proceso y de Laudan acerca de la objetividad de los estándares contribuyen a la ansiada racionalización de las decisiones judiciales.

Palavras-chave: búsqueda de la verdad; pruebas; epistemología; estándares de prueba; razonamiento probatorio.

\begin{abstract}
This essay aims to explore the pursuit of the truth as one of the main goals of the juridical process, based on Michele Taruffo's conception. Thus, an interesting approach is to recognize that procedures of facts verification should be guided by fundamental epistemological notions to establish the best way to approach the truth. In this context, it is possible to conclude that the proof legal standards will only be capable to fulfill its role to determinateif it's possible to consider the main facts as proved if established by objective and rational means, as argued by Larry Laudan. Taruffo's conceptions about the truth in the process and Laudan's view about the objectivity of the standards contribute to the awaited rationalization of judicial decisions.
\end{abstract}

Keywords: Truth finding; evidence; epistemology; standards of proof; evidential reasoning.

\title{
Introdução
}

Existem opiniões muito variadas em torno do problema de se a verdade dos fatos possa ou deva ser considerada como uma finalidade do processo judicial, bem comoem que medida e sob quais limitações deva ser buscada.

A despeito de não ser este um questionamento novo, nem tampouco próprio da ciência jurídica, já que presente também na cultura filosófica, bem como objeto de estudo de outras ciências, o problema da definição da verdade segue relevante e não parece caminhar para um consenso.

Interessante ressaltar que, para além de se estabelecer uma adequada definição de verdade, o que passa necessariamente por uma análise filosófica e será tratado em seguida, é patente que a verdade é um valor de extrema relevância no âmbito do Estado Democrático de Direito.

A verdade buscada no processo não é distinta da que se busca em outras ciências. A mais significativa diferença é que a atividade processual possui algumas regras 
específicas guiadas por outros valores -igualmente relevantes-e que acabam por condicionar e limitar tal descoberta. Apesar disso, a função primordial do processo e da atividade probatória é a determinação da verdade dos fatos, compreendida em sua concepção de correspondência com a realidade exterior.

Importa deixar consignado que instituir tal objetivo não significa defender ingenuamente que a decisão adotada sobre os fatos corresponderá, necessariamente, à afirmação da verdade dos mesmos, tal como ocorreram na realidade. No entanto, também não é razoável admitir as concepções que defendem que a decisão adotada corresponde unicamente à crença (ou convicção) do juiz acerca da verdade. A crença situa-se no plano subjetivo e, portanto, insuscetível de controle, o que torna tal visão inapropriada.

Afigura-se mais adequado, portanto, a compreensão da decisão sobre os fatos no sentido da aceitação pelo julgador da verdade de uma dada proposição, em razão de ter a mesma atingido um certo grau de confirmação exigido porum parâmetro aplicável ao caso, com base nos elementos probatórios disponíveis. Isso significa que o juiz deverá valorar as provas segundo os critérios racionais, decidindo em favor da hipótese que possui amplo suporte corroborativo a partir do conjunto probatório, de modo a satisfazer os referenciais de decisão estabelecidos juridicamente. Vale lembrar que isso deve ser feito a despeito de o quão intimamente convencido esteja ele acerca da verdade da hipótese contrária, uma vez que se reconhece a diferença entre "crença" e "prova". Crer na verdade de um enunciado não é razão suficiente para considerá-lo provado. Esta última hipótese depende da satisfação de parâmetros objetivos $^{1}$.

Por outro lado, a liberdade atribuída ao julgador para formar seu convencimento não deve ser concebida como autorização para decidir segundo sua intuição. A ação de julgar deve ser concebida como uma atividade racional, científica e fundamentada nas provas praticadas, conforme Miranda Estrampes ${ }^{2}$. Deste modo, "el juzgador deberá valorar, ineludiblemente, las pruebas de acuerdo con las 'reglas de la sana crítica', del 'criterio racional' o del 'criterio humano'; es decir, de acuerdo con las reglas de la lógica, de la psicología, de la sociología y de la experiencia”.

Paralelamente, considerando-se que no processo a verdade é geralmente concebida em termos de probabilidade, dada a falibilidade do conhecimento humano, o convencimento judicial poderá ser, nesses termos, mais ou menos sólido, a depender do conjunto probatório levado à sua apreciação. Para tanto, entram em

$1 \quad$ Sobre o tema ver: BELTRÁN, Jordi Ferrer. Prueba y Verdad en el Derecho. Madrid: Marcial Pons, 2005.

2 MIRANDA ESTRAMPES, Manuel. La mínima actividad probatoria en el proceso penal. Barcelona: J. M. Bosch, 1997, p. 125.

3 MIRANDA ESTRAMPES. Op. cit. p. 153. 
Os standards probatórios como métrica da verdade: em busca de parâmetros objetivos

cena os chamados standards de prova. Também compreendidos como quantum of proof, conforme Ian Dennis ${ }^{4}$, referem-se ao grau de probabilidade segundo o qual os fatos devem ser provados para serem tidos como verdadeiros.

Em um primeiro momento será abordada a concepção da verdade que se considera mais acertada dentro da dinâmica processual a fim de orientar a configuração da atividade probatória, o que se fará principalmente a partir das posições defendidas por Michele Taruffo.

Paralelamente, considerando que a definição judicial da verdade dos fatos no processo não pode se limitar à subjetividade de seu convencimento, exsurge a relevância da fixação de determinados graus de confirmação a serem atingidos a depender do conjunto probatório disponível, os quais poderão ser mais ou menos rigorosos em face da matéria e dos bens jurídicos tutelados. É nesse contexto que entra em relevo o alerta de Larry Laudan sobre a necessidade de que esses standards sejam estabelecidos de forma objetiva, sob pena de sua total inutilidade. Em vista disso, a segunda parte do trabalho buscará apresentar as observações do autor e suas propostas destinadas a reduzir os riscos de subjetividade na determinação judicial da verdade.

Parece relevante aliar a visão da busca da verdade, da maneira tratada por Michele Taruffo, especialmente no tocante à dimensão epistêmica do processo, com as observações de Larry Laudan, no sentido da necessidade de fixação de standards probatórios objetivos. Tais posições se completam e parecem caminhar rumo à almejada racionalização das decisões judiciais.

\section{A verdade como valor}

Analisando a verdade como valor nos âmbitos social, político e jurídico, Taruffo ${ }^{5}$ procura estabelecer algumas premissas importantes.

Em primeiro lugar, em relação à verdade como valor social, esta teria uma função importante no aspecto moral, o que, segundo o autor, estaria relacionado às regras que cada pessoa segue ou não em seu comportamento dentro de uma sociedade. Sendo assim, é difícil apontar um sistema ou conjunto de regras morais em que não se preze pela verdade e não seja condenada a falsidade ${ }^{6}$.

Da mesma forma,quando se pensa em qualquer sistema ético, é muito difícil imaginar algum que legitime a mentira, de modo a ser cabível afirmar que a verdade

\footnotetext{
4 DENNIS, Ian. The Law of Evidence. 4th ed. London: Sweet \& Maxwell, 2010. p. 450.

5 TARUFFO, Michele. La Verdad como Valor Social y Jurídico. In: Proceso y decisión: lecciones mexicanas de Derecho Procesal. Madrid: Marcial Pons, 2012. p. 41.

$6 \quad$ Ibidem.
} 
cumpre uma função importante no entorno da vida em sociedade. $\mathrm{O}$ autor frisa, com respaldo nos teóricos da comunicação social, que a própria comunicação entre os indivíduos tem como pressuposto um dever de dizer a verdade, eis que não se poderia legitimar uma comunicação baseada em falsidades ${ }^{7}$.

No aspecto político, no âmbito dos sistemas democráticos, ainda maior seria o valor atribuído à verdade, já que esta deve nortear as relações de poder estabelecidas entre os seus detentores e os cidadãos. Se a verdade não se apresenta em uma medida correta nessas relações, estar-se-á diante de um déficit de democracia.

$\mathrm{O}$ autor lembra que historicamente os sistemas totalitaristas foram fundados na mentira, repetindo o slogan de Joseph Goebbels, ministro da propaganda do Reich, para quem "uma mentira repetida mil vezes acaba se tornando verdade"; e também Stalin, que ordenava que se alterassem os livros de história, não para adequá-los à realidade, mas para ajustá-los ao que ele considerava apropriado e conveniente. Taruffo conclui que o valor político da verdade é um dos elementos da Democracia ${ }^{8}$.

É claro que algumas estratégias do exercício do poder político podem limitar essa verdade em virtude de questões relevantes de ordem pública ou de segurança nacional. Porém, deixar de revelar a verdade de modo fundamentado e com base em outros valores relevantes não significa legitimar uma mentira ou faltar com a democracia.

Em seguida, finalmente, o autor se põe a analisar se seria a verdade também considerada um valor jurídico. Já de antemão explica que em uma determinada sociedade na qual a verdade é um valor moral que pauta a vida social, as comunicações e também a política, não seria possível deixar de admitir a verdade como valor no âmbito do Direito. Seria como dizer que o Direito não tem qualquer relação com a moral ou com o funcionamento da sociedade.

\section{A verdade e o processo}

No âmbito do Direito, as normas previstas abstratamente pelo legislador pressupõem, para sua concretização, uma determinada situação fática verificada na realidade. No direito penal, por exemplo, deve ser aplicada a pena para quem pratique uma determinada conduta prevista. Se não há uma preocupação em apurar, verdadeiramente, se a conduta foi ou não praticada na realidade para que, somente então, seja a pena aplicada, o direito será um mecanismo de perpetuação de injustiças. Assim sendo, uma correta aplicação do direito pressupõe uma adequada verificação dos fatos lastreada na verdade, motivo pelo qual não há como desvincular Direito e verdade.

\footnotetext{
$7 \quad$ Ibidem.

$8 \quad$ Ibidem. p. 42.
} 
Os standards probatórios como métrica da verdade: em busca de parâmetros objetivos

No mesmo sentido Greco ${ }^{9}$ ressalta que "a ideia de Justiça como objeto do Direito sempre esteve axiologicamente ancorada no pressuposto da verdade, ou seja, na incidência das normas jurídicas sobre a realidade da vida tal como ela é". E continua, constatando que "os indivíduos somente se sentem eticamente motivados a conviver sob o império da lei, quando sabem que a justiça vai dar a cada um o que é seu, em conformidade com a verdade".

Não se pode olvidar, como ainda alerta o professor, que uma das maiores ilusões que a consciência democrática contemporânea pode difundir na sociedade é a de que, no Estado de Direito, todo aquele que tiver um direito lesado ou ameaçado receberá do Estado a mais ampla e eficaz tutela jurisdicional apta a lhe assegurar o seu pleno gozo. Isso porque, apesar de ser certo que o direito nasce dos fatos, até hoje não houve nenhuma ciência ou saber humano que fosse capaz de empreender sua reconstrução de forma absolutamente segura e aceita por todos, para que o juiz pudesse se limitar a dizer o direito aplicável ${ }^{10}$.

Essa reflexão acerca de se a verdade está ou não ao alcance do juiz por meio do processo foi responsável por originar uma série de concepções céticas que inclusive chegam a negar a verdade como um fim do processo.

Taruffo analisa essas concepções céticas em três perspectivas: a de impossibilidade teórica;ade impossibilidade ideológica e ade impossibilidade prática de o processo alcançar a verdade.

Sobre a impossibilidade teórica, estaria ela relacionada com uma negação geral da possibilidade de se estabelecer a verdade de qualquer coisa. Esta concepção vem relacionada a um ceticismo filosófico radical que exclui a cognoscibilidade da realidade ${ }^{11} . \mathrm{O}$ autor apontaos argumentos das correntes filosóficas que sinalizam para a impossibilidade teórica de alcançar a verdade no processo, dentre os quais, são citados aqueles que sebaseiam em premissas de psicologia ou de sociologia do conhecimento. Em relação às primeiras, cuidam dos argumentos da falibilidade $\mathrm{e}$ imprecisão, complexidade e variabilidade dos métodos cognoscentes, impeditivos à obtenção de um conhecimento verdadeiro dos fatos, especialmente no âmbito do processo. Em relação às segundas, seriam os argumentos segundo os quais os procedimentos cognitivos estão impregnados por condicionantes sociais que determinam a inexistência de uma forma objetiva de apuração dos fatos de um modo geral, bem como no âmbito específico do processo ${ }^{12}$.

\footnotetext{
9 GRECO, Leonardo. Instituições de Processo Civil. Vol. II. Rio de Janeiro: Forense, 2011. p. 92.

$10 \quad$ Ibidem. p. 83.

11 TARUFFO, Michele. La Prueba de los Hechos. Trad. Jordi Ferrer Beltrán. Madrid: Trotta, 2005. p. 28.

$12 \quad$ Ibidem. p. 35.
} 
Taruffo cita também algumas concepções de impossibilidade ideológicae práticaque desvinculam o processo da busca da verdade, no que explica que há ao menos dois tipos de razões pelas quais o conceito de verdade dos fatos no processo é altamente problemático no plano da definição do papel das provas ${ }^{13}$.

O primeiro tipo de razões, que se liga às concepções de impossibilidade prática de alcançar a verdade, refere-se à contradição entre verdade formal (ou processual) -que se estabelece no contexto do processo, e verdade real- que somente seria apurada fora do processo. Essencialmente, se trata de saber se há identidade entre essas duas concepções. Segundo os juristas, haveria, de um lado, uma verdade processual, estabelecida no processo por meio das provas e pelos procedimentos probatórios e, por outro lado, a verdade material, histórica, insuscetível de ser alcançada pelas provas judiciais. No entanto, como fora bem observado, essa distinção é inaceitável, vez que parece insustentável a ideia de uma verdade judicial totalmente distinta e autônoma da verdade ocorrida no espaço e no tempo.

Como mostra o autor italiano, a justificativa para essa distinção parece consistir na circunstância de que no processo existem normas relativas à atividade probatória, que acabam por, inevitavelmente, condicionar a apuração dos fatos, além também da existência de regras que põem fim à busca da verdade (como exemplifica o autor com a coisa julgada). Ao contrário, fora do processo, não haveria qualquer tipo de limitação à busca da verdade ${ }^{14}$.

Ainda com Taruffo, sobre as regras probatórias que podem limitar ou condicionar a busca da verdade, não significa que estas levem a uma verdade diferente da que se possa descobrir fora do processo. O que ocorre é um déficit na apuração da verdade que ocorre no processo em virtude de regras que limitam a introdução de provas relevantes à apuração dos fatos, o que pode levar a uma verdade limitada, incompleta, ou, nos casos mais graves, não se apura verdade alguma. Finaliza o autor asseverando que o problema não concerne à verdade, mas aos limites dentro dos quais a disciplina do processo consente que essa seja apurada.

O segundo tipo de razões para a problemática que envolve a prova e a verdade dos fatos se refere ao lugar que se atribui à verdade na teoria do processo, o que se relaciona com as concepções de impossibilidade ideológica de se alcançar a verdade. Para os que consideram que a função do processo é tão somente a de colocar fim às controvérsias, conforme Taruffo, tende-se a excluir que este deva ser orientado para a comprovação da verdade dos fatos. Nesse sentido, a busca da verdade poderia até mesmo ser vista como obstáculo prático para a consecução rápida do fim de solução da controvérsia. Quem, por outro lado, considera que a função do processo

$13 \quad$ Ibidem. p. 24.

14 TARUFFO, Michele. Uma simples verdade: o juiz e a construção dos fatos. Trad. Vitor de Paula Ramos. São Paulo: Marcial Pons, 2012.pp. 106 - 107. 
Os standards probatórios como métrica da verdade: em busca de parâmetros objetivos

é a aplicação da lei ao caso concreto, a concretização de direitos e a garantia efetiva dos direitos fundamentais, tende a atribuir à comprovação da verdade dos fatos um valor instrumental, que se deve perseguir em vista do fim principal do processo representado pela formulação de uma decisão juridicamente correta ${ }^{15}$.

É comum encontrar teorias que resolvem o impasse simplesmente afirmando que não é objetivo do processo a busca da verdade, visto que seu objetivo seria simplesmente a resolução das controvérsias e não a produção de decisões verdadeiras. Assim, a única verdade que interessaria ao processo seria aquela estabelecida pelo juiz na sentença já que, fora esta, nenhuma outra é do interesse do Estado, da administração da justiça ou, muito menos, das partes. Porém, como o próprio autor observa, apoiado nas lições de Twining, essa constatação leva a uma contradição entre a teoria da prova e a teoria do processo. A primeira estabelece que a função da prova consiste em estabelecer a verdade dos fatos, enquanto a segunda diz, ao contrário, que a função do processo não consiste, em absoluto, na determinação da verdade dos fatos. Restaria inexplicado, assim, para que serviriam as provas no processo, já que estas estão dirigidas a produzir resultados nos quais o processo não estaria interessado ${ }^{16}$.

Parece equivocado afirmar que o processo não estaria interessado na determinação da verdade dos fatos, até porque, mesmo que se conceba o processo como instrumento para resolver conflitos, essa resolução não seria justa enquanto totalmente dissociada da verdade histórica.

Como bem constatou Greco, a sociedade do nosso tempo não mais se contenta com qualquer reconstrução dos fatos, mas apenas com aquela que a consciência coletiva assimila e aceita como autêntica, porque a exata reconstituição dos fatos é um pressuposto fundamental de decisões justas e da própria eficácia da tutela jurisdicional dos direitos ${ }^{17}$.

No entanto, uma decisão judicial que se pretende por justa -e é certo que a justiça das decisões é um valor a ser tutelado em um Estado Democrático de Direito- deve estar inequivocamente assentada em pressupostos fáticos verdadeiros, o que, por sua vez, depende de uma atividade adequada de reconstrução dos fatos.

Ademais, o estudo da prova e a busca pela verdade ${ }^{18}$, como condições para se atingir os mais importantes objetivos da atividade processual, assim como a respon-

15 TARUFFO, Michele. Consideraciones sobre Prueba y Verdad. In: __. Sobre las fronteras: Escritos sobre la justicia civil. Trad. Beatriz Quintero. Bogotá: Editorial Temis, 2006. p. 263.

16 TARUFFO, Michele. La Prueba de los Hechos. Op. cit. pp. 26-27.

17 GRECO, Leonardo. "A Verdade no Estado Democrático de Direito". In: __ . Doutrinas Essenciais de Direito Civil. vol. 1. São Paulo: Revista dos Tribunais, 2010. p. 495.

18 "A própria estrutura do processo civil depende do problema da verdade, e, então, não se trata de uma simples adaptação técnica do instrumento judiciário a um objetivo determinado, 
sabilidade social impregnada no processo, nunca tiveram tanta relevância como nos dias atuais, com a natural evolução das sociedades, e, portanto, do próprio direito. Neste sentido, "a progressiva humanização do processo acarretou, em primeiro lugar, a destruição do primado simbólico e religioso da forma e depois obrou com que se atribuísse maior importância aos seus fins sociais e políticos"19.

A partir daí a prova assumiu posição de destaque no relevo do processo, seja por representar uma "ponte" entre o direito material e o processual, seja por constituir o caminho imprescindível para que o processo perquira seu fim, qual seja, a determinação verdadeira dos fatos.

\section{A dimensão epistêmica do processo e os standards de prova}

Como já anteriormente enfatizado, a verdade buscada no processo não é distinta da que se busca em outras ciências, a mais significativa diferença é que a atividade processual possui algumas regras específicas guiadas por outros valores -igualmente relevantes- e que acabam por condicionar e limitar a descoberta da verdade.

Mesmo que seja cediço que a natureza humana não é capaz de chegar a uma verdade absoluta, considera-se um dever de honestidade empenhar-se com todas as forças a fim de se aproximar o máximo possível deste ideal. Deste modo, no processo, mesmo com o convencimento de que a sentença final pode não ser mais que um juízo de verossimilhança, é mister que todo o procedimento esteja ordenado a fazer a mais profunda e controlada investigação possível da verdade tal como ela é, de modo a se reduzir ao mínimo a distância entre esta e aquela alcançada pelo processo.

Nesta esteira, uma decisão que se quer por justa não pode se contentar com qualquer verdade fática, emanada do arbítrio do julgador, sob pena de transformar o direito subjetivo em um direito aleatório, como assevera Leonardo $\mathrm{Greco}^{20}$, conforme os fatos dos quais resulta fossem reputados verdadeiros ou não segundo a conveniência do juiz, suportando a possibilidade de, diante das mesmas provas, outro juiz recusar essa veracidade. O autor continua a indagação citando Gian Franco Ricci,

mas se trata, sobretudo, de uma escolha de natureza política no que respeita às formas e aos objetivos da administração da justiça civil. No processo, com efeito, a verdade não é um fim em si mesma, mas é necessário buscá-la enquanto condição para que haja uma justiça "mais justa”. MICHELI, Gian Antonio; TARUFFO, Michele. "A prova”. Tradução Teresa Celina de Arruda Alvim. Revista de Processo. São Paulo. n.16. out/dez 1979. p. 168.

19 OLIVEIRA, Carlos Alberto Álvaro de. Do formalismo no processo civil. 2.ed. São Paulo: Saraiva.,2003. p. 217 - 218.

20 GRECO, Leonardo. A prova no processo civil: do Código de 1973 ao novo Código Civil. In: ___ Estudos de Direito Processual. Campos dos Goytacazes: Faculdade de Direito de Campos, 2005. pp. 357 - 392. 
Os standards probatórios como métrica da verdade: em busca de parâmetros objetivos

no sentido de que o acertamento da verdade deve ser o único modo para o processo atingir os seus fins, devendo este ser demonstrativo,e não simplesmente retórico, valendo-se de preferências pessoais do julgador ${ }^{21}$.

A fim de se alcançar a desejada verdade do processo, Augusto Morello, da escola processual argentina, aponta que deve-se manejar, e ter à disposição, um procedimento que facilite e concorra para a obtenção desta verdade, com oportunos e necessários fatores para a eficácia de tal mecanismo, dentre outros que se dispõe a tais propósitos, representando "linhas de tendências": a redução de regras de exclusão dos meios de prova; a introdução de instrumentos que assegurem a aquisição da prova; a extensão do poder de iniciativa instrutória do juiz; a adoção de um método eficaz para a assunção e prática da prova; o critério de livre valoração da prova ${ }^{22}$.

Tal flexibilização da questão probatória na seara processual argentina também se reflete no processo de família, onde Kielmanovich aponta como princípio norteador dos conflitos complexos de família o princípio do favor probationes, sugerindo que nos casos de dúvidas objetivas e especialmente de dificuldades probatórias, deve-se optar por um critério amplo em favor da produção, admissão e eficácia das provas, além de uma profunda e sensível exploração da pessoa e de seu entorno:

“(...) Así, si se repara en las dificultades que apareja, por ejemplo, la demostración del adultério, la filiación, la impotencia, etcétera, fácilmente se concluye que el Derecho, y en particular el derecho procesal familiar, ha debido encontrar nuevas técnicas para permitir y favorecer la reconstrucción de hechos que, como los mencionados, no suceden a la luz del día ni a la vista de terceros, y se rodean, antes bien, de recaudos que deliberadamente apuntan a impedir su prueba o a tornarla muy dificultosa"23.

A partir do momento em que se compreende a verdade como um valor importante a orientar os esforços empregados na dinâmica processual, cumpre analisar se, e em que medida, o processo pode ser considerado "um instrumento epistemologicamente válido e racional, ou seja, se esse é um método eficaz para a descoberta e a determinação da verdade dos fatos em que se funda a decisão" ${ }^{2425}$, a despeito das regras procedimentais peculiares que o caracterizam.

\footnotetext{
$21 \quad$ Ibidem.

22 MORELLO, Augusto. La prueba: tendencias modernas. 2. ed. La Plata: Libreria Editora Platense, 1998. p. 42.

$23 \quad$ KIELMANOVICH, Jorge. Procesos de Familia. Buenos Aires: Abeledo - Perrot, 1998. p. 22.

24 TARUFFO, Michele. Uma simples verdade: o juiz e a construção dos fatos. Trad. Vitor de Paula Ramos. São Paulo: Marcial Pons, 2012. p. 159.

25 Em sentido semelhante: LAUDAN, Larry. Verdad, error y proceso penal: un ensayo sobre epistemología jurídica. Madrid: Marcial Pons, 2013; DAMAŠKA, Mirjan. "Epistemology and legal regulation of proof”. In: Law, probability and risk. n 02, 2003. pp. 117 - 130.
} 
O procedimento probatório, em seu conjunto, engloba diferentes fases que vão desde a postulação e consequente admissão, passando pela efetiva produção e culminando com a valoração das provas, esse, sem dúvida, o momento mais relevante, vez que nele se concentra todo o resultado da atividade probatória. Em sendo a prova o instrumento de que se vale o juiz e as partes para estabelecer a verdade dos fatos $-\mathrm{o}$ que não é diferente do que ocorre na investigação dos fatos nas mais variadas áreas do conhecimento- , é pertinente a análise geral acerca das normas que disciplinam esse procedimento probatório, a fim de verificar se são capazes de conduzir o julgador por um processo de decisão racionalmente válido e se podem ser consideradas epistemologicamente adequadas para este propósito ou se, em sentido contrário, atuam por finalidades outras que não a da descoberta da verdade. Paralelamente, identificando-se as normas contra-epistêmicas, deve-se verificar se sua manutenção é indispensável e justificável por outros valores igualmente relevantes, bem como o que pode ser feito para atenuar os efeitos desse desvio ${ }^{26}$.

Larry Laudan, grande epistemólogo norte-americano, realiza interessante análise acerca da perspectiva epistêmica do processo penal. $\mathrm{O}$ autor alude a três conjuntos de valores que normalmente governam os sistemas de justiça penal. Um primeiro conjunto seria composto de valores extra-epistêmicos, que se relacionam às normas que visam a proteger os direitos do acusado, o devido processo legal, dentre outros, mas nenhum deles voltado à busca da verdade. O segundo conjunto de valores é denominado pelo autor de núcleo duro da epistemologia jurídica e se compõe pelas normas que visam reduzir ou minorar a probabilidade de um juízo errôneo. Finalmente, o terceiro grupo de valores é denominado por Laudan como núcleo débil da epistemologia jurídica, onde o interesse das normas não é em reduzir os erros na busca da verdade, mas em distribuí-los de uma maneira particular, segundo uma decisão política de acordo com a qual certo tipo de erro é menos aceitável que outro $^{27}$.

26 Tendo em vista a concepção de prova como direito e dentro da perspectiva de sua função demonstrativa, quanto maior a gama de informações disponíveis ao juiz para que desenvolva essa função cognitiva, mais próximo estará da descoberta da verdade. Por esse motivo, as limitações probatórias devem ser analisadas com certa cautela para evitar qualquer tipo de entrave à função epistêmica do processo. É certo que alguns desses obstáculos que poderão representar uma maior dificuldade na descoberta da verdade se justificam no processo para salvaguardar outra ordem de valores e, por tal motivo, deverão ser mantidos para evitar que o processo represente uma violação indevida a direitos igualmente relevantes. Conforme salienta Greco, "a verdade não pode ser obtida a qualquer preço, pois o Estado de Direito, assentado na dignidade de todos os seres humanos e na eficácia concreta dos seus direitos fundamentais, não pode admitir que a tutela dos direitos de uns se faça com o sacrifício de um núcleo intangível dos próprios direitos fundamentais de outros". Cf. GRECO. Instituições de Processo Civil. Op. cit. p. 120.

$27 \quad$ LAUDAN. Op. cit. p. 97. 
Os standards probatórios como métrica da verdade: em busca de parâmetros objetivos

Assim, a partir de uma escolha política de que condenar um inocente é mais abominável que absolver um culpado, algumas normas se dirigem a direcionar os eventuais erros nas decisões para a segunda hipótese. O processo penal possui várias diretrizes nesse sentido, como a presunção de inocência, o in dubio pro reo, a ideia segundo a qual a acusação é quem deve suportar o ônus da prova e, enfim, os standards probatórios.

As normas processuais destinadas a regular a atividade probatória abrangerão as diferentes fases que dizem respeito ao direito à prova, quais sejam, o direito à admissão processual das provas relevantes para demonstrar a veracidade dos fatos e à sua efetiva produção, e o direito à sua valoração racional pelo julgador, culminando em uma decisão justa. Em cada um desses momentos podem ser compreendidas as regras que dispõem, respectivamente, sobre a formação do conjunto probatório (onde se situam as eventuais limitações probatórias e as consequentes regras de exclusão de provas), seguidas das que tratarão do procedimento para sua produção, além das diretrizes para nortear a atividade valorativa do julgador, as quais trarão os parâmetros a serem considerados no momento de decidir a favor de uma ou outra hipótese fática.

Para que se possa alcançar um modelo de processo que se amolde aos ditames de uma concepção racionalista da prova é necessário adequar o procedimento probatório ao fim da determinação da verdade dos fatos segundo um ideal de correspondência, o qual conceba a prova como instrumento metajurídico apto a realizar a verificação das hipóteses segundo os métodos adequados da investigação científica.

Os cânones racionais da ciência podem ajudar o julgador no raciocínio sobre as provas de modo a verificar o que se pode racionalmente inferir a partir do conjunto probatório disponível. A valoração permitirá outorgar a cada uma das hipóteses fáticas em conflito um determinado grau de confirmação - que nunca será igual à certeza absoluta. Porém, a questão da definição do quantum de confirmação se faz necessário para que se possa considerar uma hipótese como provada ou não, já não é mais uma questão científica, é uma decisão política ${ }^{28}$.

No caso do processo penal, por exemplo, o método científico de valoração só permite dizer que a hipótese de o réu ser culpado possui maior suporte probatório do que a dele ser inocente. Porém, a definição do quanto de suporte probatório é necessário para que se possa seguramente condená-lo é uma questão a ser regulada pelo direito, de modo a distribuir as chances de erro entre as partes, de acordo com os valores em jogo.

E isso não faz com que o processo seja diferente das outras áreas, a exemplo do que ocorre em uma pesquisa farmacêutica para considerar a eficácia de certo medica-

28 Nesse sentido, BELTRÁN, Jordi Ferrer. La valoración racional de la prueba. Madrid: Marcial Pons, 2007. 
mento:a decisão acerca de sua segurança também estará sujeita a um determinado standard a ser definido pela comunidade farmacêutica, de modo que normalmente deverá exigir uma margem grande de segurança em virtude dos potenciais riscos de danos à saúde. Por outro lado, o standard do historiador é normalmente mais baixo, já que os valores envolvidos e uma eventual hipótese de erro não são tão prejudiciais.

Para o presente ensaio, serão alvo de análise apenas as questões relativas à atividade valorativa no que toca aos standards de prova -que exprimem o grau de convencimento exigido para lastrear uma decisão-, mais especificamente o standard que costuma ser exigido para uma condenação penal. O problema que se apresenta, em consonância com o anteriormente exposto, é a excessiva subjetividade que permeia a formação do convencimento do julgador, o que é agravado pelo caráter subjetivo dos standards de prova, como relatou Laudan ${ }^{29}$. A subjetividade do standard implica no afastamento do processo ao fim almejado da busca da verdade em seu ideal de correspondência, ficando muito mais próximo, ao contrário, das concepções subjetivas de verdade, as quais consideram a formação do convencimento do julgador como objetivo primordial do processo.

A análise de Laudan parte de uma perspectiva inerente ao direito anglo-americano, onde são três os mais conhecidos standards de prova comumente utilizados, quais sejam, evidence beyond a reasonable doubt, para casos criminais, preponderance of evidence nos casos civis e clear and convincing evidence também utilizado em causas civis, mas naquelas em que se põe em pauta a liberdade individual ${ }^{30}$.

O preponderance of evidence seria o critério menos exigente em termos de prova, requer a verificação se o autor da pretensão provou os fatos de modo que estes pareçam mais prováveis de serem verdadeiros do que falsos. Paralelamente, em alguns casos cíveis utiliza-se o clear and convincing evidence, que está situado em uma escala intermediária entre o anterior, de menor grau de probabilidade e o padrão criminal, que exige um maior rigor. Esse padrão justifica-se em algumas causas que, por haver uma certa restrição de direitos, exigiria uma maior carga probatória, embora não chegue a se assemelhar ao alto padrão de exigência para os casos criminais.

29 LAUDAN. Op. cit. No mesmo sentido, em obra mais abrangente: Verdad, error y proceso penal: un ensayo sobre epistemología jurídica. Madrid: Marcial Pons, 2013. pp. 59 e ss.

30 Garapon estabelece uma escala imaginária para comparação entre os três padrões de prova, sendo que o criminal, evidence beyond a reasonable doubt, exigiria uma probabilidade de mais ou menos $75 \%$, enquanto o cível, preponderance of evidence exige mais de $50 \%$ de probabilidade. Em terceiro lugar, o clear and convincing evidence, situado em lugar intermediário, exigiria um nível de 60 a 65\% de probabilidade. GARAPON, Antoine; PAPAPOULOS, Ioannis. Julgar nos Estados Unidos e na França. Cultura Jurídica Francesa e Common Law em uma Perspectiva Comparada. Trad. de Regina Vasconcelos. Rio de Janeiro: Lumen Juris, 2008. p. 108. 
Os standards probatórios como métrica da verdade: em busca de parâmetros objetivos

Em terceiro lugar, sendo este o objeto da presenteanálise, situa-se o evidence beyond a reasonable doubt, em que se exige que a prova da acusação esteja além de uma dúvida razoável. Isso não significa que não possa haver dúvida, pois parte-se do pressuposto que esta sempre existirá, vez que a plena certeza é praticamente inacessível. O que se exige, outrossim, é que o fato adquira um certo grau de probabilidade que afaste a existência de qualquer dúvida que se mostre razoável sobre sua culpa, sendo esta entendida não como qualquer dúvida possível, mas como uma dúvida substancial surgindo sobre a prova ${ }^{31}$. No processo penal norte-americano o standard é direcionado, principalmente, aos jurados, uma vez que naquele contexto a instituição do júri ainda é muito presente.

Sendo assim, os jurados, após se deterem sobre as provas apresentadas pela acusação e defesa, devem decidir por condenar o acusado se, e somente se, tiverem chegado a um grau de certeza de que ele cometeu o delito, além da dúvida razoável. Por outro lado, se persiste uma dúvida razoável de que ele possa não ter cometido, deverão absolvê-lo.

Laudan se refere a um entendimento recorrente entre os juristas acadêmicos de se referir ao standard em termos de probabilidade bayesiana, quantificando-o em uma probabilidade de $90 \%$ a $95 \%$ de certeza. Por outro lado, os juízes preferem tratar o standard qualitativamente, como uma certeza moral, uma convicção íntima, firme, acerca da culpabilidade. $\mathrm{O}$ autor pretende demonstrar, no entanto, que ambos os juristas (acadêmicos e profissionais) não têm mais que uma compreensão superficial do que seja um standard probatório e do porquê de sua necessidade ${ }^{32}$.

O maior problema dos standards é, na visão do autor, a subjetividade de sua formulação e a falta de um método para sua aplicação e verificação. Quando se trata do júri, os juízes presidentes não fazem qualquer esforço para explicar aos jurados quais tipos de inferências ou que classe de evidências justificariam a formação de uma crença firme na culpabilidade do acusado, como se a simples expressão "dúvida razoável" fosse auto-evidente. Laudan explica que o ponto de vista oficial da Suprema Corte dos Estados Unidos acerca do standard é de que a condição

31 Sobre a formação do convencimento do julgador, MITTERMAIER estabelece: “Todas estas impresiones, todos estos impulsos en diversos sentidos, que los hechos producen en el juez establecen una especie de lucha entre los motivos en pro y en contra, y los que triunfan forman la convicción. La aguja de la balanza de la conciencia, por servirnos también de esta metáfora conocida, va y viene antes de fijarse, y sus movimientos establecen la proporción entre las razones de creer y negar los hechos en cuestión. Así, cuando las razones afirmativas la inclinan por su número y su peso, de tal suerte que ya no hay lugar ni aun a que suponer como posible la negativa, adquirimos la convicción positiva, al paso que si hay equilibrio, quedamos en la duda”. MITTERMAIER, C. J. A. Tratado de la prueba en materia criminal. Madrid: Imprenta de la Revista de Legislación, 1857. p. 58.

32 LAUDAN. Op. cit. pp. 98 - 99. 
necessária e suficiente para condenar o acusado em um juízo penal é a crença firme da culpabilidade por parte do jurado ${ }^{33}$.

Veja-se com isso que toda a definição do standard e sua condição de verificação depende unicamente de um critério de certeza, um estado de firme crença, o qual constitui um convencimento inteiramente subjetivo, próprio de cada indivíduo e insuscetível de controle. Diante das mesmas provas apresentadas em um determinado caso, um corpo de jurados pode chegar a uma conclusão pela condenação, por estarem intimamente convencidos da culpa do acusado, enquanto outro, (considerando que o mesmo caso fosse submetido a outros jurados), poderia considerar existente uma dúvida razoável que obstaria a condenação. E tudo isso sem qualquer possibilidade de se compreender qual foi o raciocínio dos jurados, uma vez que ainda são predominantes os veredictos imotivados.

Em sendo o standard justamente um mecanismo destinado a nortear o julgador a decidir, é inconcebível que este, ao estabelecer o grau de convencimento que deve estar presente, se mostre inteiramente subjetivo e direcione sua aplicação para o âmbito particular da certeza individual, íntima. Quando foram analisadas anteriormente as concepções de verdade, procurou-se frisar que aquelas subjetivas são inadequadas para estabelecer o padrão aceitável da verdade que se busca no processo. Já alertando para o problema, a seguinte indagação fora feita por Greco: "será que a contingência do conhecimento científico deveria levar o jurista a contentar-se com a ideia de certeza em lugar da ideia de verdade?" A resposta foi, inevitavelmente, negativa:

"A ideia de certeza é restritiva em relação à de verdade, porque pode representar apenas um juízo subjetivo meramente resultante de uma persuasão retórica, ou até mesmo um juízo formal induzido por prescrições legais inteiramente distanciadas de qualquer fundamentação científica. Penso que não. A verdade, com os significados garantístico e político acima mencionados, tem de ser objetivamente controlável e controlada, para aproximar o processo da justiça, tendendo à reconstrução mais fiel possível dos fatos da causa. Para isso, o método da prova judiciária não pode diferir substancialmente do método de investigação das ciências experimentais, adotando critérios lógico-racionais comuns a essas ciências"34.

Assim, a construção do standard e sua aplicação deve orientar o julgador a utilizar raciocínios válidos, semelhantes aos científicos, para verificar se uma hipótese pode ou não ser considerada provada diante das evidências apresentadas. Nesse sentido, Laudan explica que a finalidade de um standard em outras áreas de conhecimento científico (como nas ciências naturais, nas pesquisas clínicas em medicina, na

\footnotetext{
$33 \quad$ Ibidem. pp. 99 - 100.

$34 \quad$ GRECO. Op. cit. p. 96. 
Os standards probatórios como métrica da verdade: em busca de parâmetros objetivos

matemática, etc.) é de indicar ao investigador quando está autorizado a considerar um fato como provado, isto é, quando a relação entre a prova ou as premissas justifica a aceitação da conclusão como provada para os propósitos pretendidos. No âmbito do processo, ao contrário, o standard é parasitário do nível de confiança do jurado acerca da culpabilidade do acusado ${ }^{35}$.

O grande equívoco em pensar assim, conforme o raciocínio do autor, é a inversão da ordem lógica das coisas. É como, segundo ele, os matemáticos estabelecerem que um teorema é verdadeiro a partir do momento em que estejam seguramente convencidos desta verdade. Ou, da mesma forma, dizer a um epistemólogo que a partir do momento que estejam plenamente convencidos de que existe uma conexão causal entre A e B, isso estaria provado. Ambas as situações seriam motivo de riso. O correto seria então, justamente o contrário, ou seja, o investigador não está autorizado a estar totalmente convencido de $\mathrm{A}$ até que (e a menos que) tenha uma prova de A (sendo que a firme convicção acerca de A não conta, em absoluto, como uma prova nesse sentido ${ }^{36}$.

Destarte, pode-se concluir que um standard de prova apropriado não depende de uma confiança subjetiva em uma hipótese, ao contrário, o standard indica quando esta confiança subjetiva está justificada. Fora do direito, a confiança racional em uma conjectura segue a sua prova, nunca a precede. No direito, tal confiança precede, certifica e, inclusive, constitui a prova ${ }^{37}$.

Face a estas constatações, Laudan apresenta algumas amostras de standards adequados que poderiam ser estabelecidos, aptos a levar o investigador (juiz ou jurado) a raciocínios válidos. O autor ressalta que não está defendendo a adoção destes, apenas apresenta uma fórmula clara e objetiva de elaboração:

“(A) Se é crível a prova acusatória ou um testemunho que resultaria difícil de explicar se o acusado fosse inocente e não é crível a prova de inocência ou um testemunho que seria muito difícil de explicar caso o acusado fosse culpado, então, condene-o. Do contrário, absolva-o.Ou, tomando as indicações de algumas das interessantes propostas de Ron Allen:(B) Se a história da acusação acerca do delito é plausível e você não pode imaginar uma história plausível que mostre o acusado como inocente, então, condene-o. Do contrário, absolva-o"38.

$35 \quad$ LAUDAN. Op. cit. p. 104.

$36 \quad$ Ibidem. pp. 104-105.

$37 \quad$ Ibidem. pp. 105-106.

38 Tradução livre. No original: “(A) Si es creíble la prueba acusatoria o un testimonio que resultaría difícil de explicar si el acusado fuese inocente y no es creíble la prueba exculpatoria o un testimonio que sería muy difícil de explicar si el acusado fuese culpable, entonces condénelo. De otro modo, absuélvalo. $\mathrm{O}$, tomando las indicaciones de algunas de las interesantes propuestas de Ron Allen: (B) Si la historia de la acusación acerca del delito es plausible 
Em sentido semelhante, o epistemólogo cita uma instrução oficial para o jurado adotada pelo Estado da Califórnia acerca das provas circunstanciais:

"A conclusão pela culpabilidade a respeito da prática de um delito não pode se basear em provas circunstanciais a menos que as circunstâncias provadas sejam não só (1) coerentes com a teoria de que o acusado é culpado do crime senão que, ademais, (2) não possam ser reconciliadas com qualquer outra conclusão racional. Se as provas circunstanciais permitem duas interpretações racionais, uma que sinaliza para a culpabilidade do acusado e a outra para sua inocência, você deverá adotar esta segunda interpretação e rechaçar a interpretação que sinaliza para a culpabilidade" ${ }^{\prime 3}$.

Veja-se que, nos três casos, são estabelecidos parâmetros dentro dos quais pode-se considerar provados ou não os fatos, bem como, para que possa o jurado condenar ou absolver o acusado. Por mais que ainda nesses casos haja uma margem para a subjetividade, a conclusão não fica inteiramente no campo da certeza, do convencimento subjetivo, aproximando-se mais da noção de verdade como correspondência que deve ser a responsável por guiar os esforços no processo.

As observações de Laudan foram submetidas ao debate em uma mesa redonda sobre o tema "Racionalidade e standards de prova", em dezembro de 2005 durante o XI Congreso Italo-Español de Teoría del Derecho, tendo como debatedores Michele Taruffo, processualista, Marina Gascón Abellán e Juan Igartua Salaverría, teóricos do direito, sob a coordenação de Perfecto Andrés Ibáñez, magistrado do Tribunal Supremo da Espanha ${ }^{40}$. Será explicitado aqui um contra-argumento em particular no que toca o tribunal do júri,para o qual serão tecidos breves comentários.

Marina Gascón Abellán compartilha com Laudan o entendimento acerca da necessidade de se estabelecer um standard de forma objetiva e controlável, aduzindo que a construção deste deve observar dois parâmetros, em primeiro lugar, decidir qual o grau de probabilidade ou certeza se requer para aceitar uma hipótese como

y usted no puede imaginar una historia plausible que muestre al acusado como inocente, entonces condénelo. De otro modo, absuélvalo". LAUDAN. Op. cit. p. 107.

39 Tradução livre. No original: "Sin embargo, el hallazgo de la culpabilidad respecto de la comisión de un delito no puede basarse en pruebas circunstanciales a menos que las circunstancias probadas sean no sólo (1) coherentes con la teoría de que el acusado es culpable del crimen sino que además, (2) no puedan ser reconciliadas con cualquier otra conclusión racional. Si las pruebas circunstanciales permiten dos interpretaciones razonables, una que señala a la culpabilidad del acusado y la otra a su inocencia, usted deberá adoptar esta segunda interpretación y rechazar la interpretación que señala la culpabilidad". LAUDAN. Op. cit. p. 108.

40 Os artigos fruto das discussões compuseram o número 28 do periódico DOXA: Cuadernos de Filosofía del Derecho, 2005, com apresentação de Jordi Ferrer Beltrán. 
Os standards probatórios como métrica da verdade: em busca de parâmetros objetivos

verdadeira; em segundo lugar, deve-se formular objetivamente o standard, ou seja, formular os critérios objetivos que indicam quando se alcança esse grau de probabilidade ou certeza exigido. Sobre esse ponto, a autora considera que essa objetividade deve se expressar mediante um critério controlável. E conclui: "Os standards se inserem, pois, em um processo de valoração racional. Mais exatamente, cumprem duas funções. Uma função heurística primeiro (enquanto guias de uma valoração racional): o standard é o critério conforme o qual deverá o juiz formular sua valoração final sobre os fatos da causa. E uma função justificadora depois (enquanto critérios para a motivação): o standard é o critério conforme o qual há de reconstruir-se a justificação da decisão probatória" ${ }^{41}$.

É acerca desta exigência de controlabilidade - totalmente pertinente e necessária, que reside um grande problema no manejo dos standards pelo júri. Problema este que não passou despercebido por Taruffo ${ }^{42}$ e Igartua Salaverría em suas observações. Considerando que na maior parte das suas configurações, especialmente no sistema norte-americano, os jurados não motivam suas decisões, restaria ineficaz a tentativa de objetivar o standard. Mesmo que se considerasse que este ainda seria útil para direcionar o raciocínio dos jurados a partir das provas, priorizando, inclusive, a sua função demonstrativa, não seria possível verificar a correção das conclusões.

Conforme Igartua Salaverría, pouco valeria haver conquistado um critério objetivo se não for possível nos blindar contra uma recaída na subjetividade. É necessário formular corretamente o standard probatório, mas pode ser que isso não seja suficiente. É preciso, primeiro, entendê-lo corretamente; logo, aplicá-lo

${ }^{41}$ ABELLÁN, Marina Gascón. "Sobre la posibilidad de formular estándares de prueba objetivos". In: DOXA: Cuadernos de Filosofía del Derecho. cit. p. 129.

42 "Un punto que creo importante es que en el sistema norteamericano el problema de la aplicación del BARD surge en dos momentos: el de las instrucciones que los jueces del trial dan al jurado y el de las afirmaciones de principio que se encuentran en las sentencias de las appellate courts o de la Corte Suprema. En cambio, no es posible en absoluto verificar si el BARD o cualquier otro estándar se ha aplicado efectivamente por los jurados en el momento de la decisión, por la obvia razón de que los jurados no motivan sus veredictos. En lo que se refiere a las instrucciones dadas por los jueces a los jurados, estas pueden ser formuladas mejor o peor según los casos, aunque sólo sea porque son dadas por jueces que no tienen formación filosófica o epistemológica (y a menudo tienen incluso una formación jurídica mediocre). En cualquier caso, la observación fundamental es que no es posible verificar si, y en qué medida, esas instrucciones son seguidas por el jurado. Se puede conjeturar que incluso si el juez ofreciese una definición filosóficamente impecable del BARD, esta no sería más que una especie de 'mensaje en la botella', que el jurado podría no comprender o no seguir". Vale observar que a sigla BARD corresponde ao standard norte-americano beyond a reasonable doubt. TARUFFO, Michele. "Tres observaciones sobre 'Por qué un estándar de prueba subjetivo y ambiguo no es un estándar, de Larry Laudan”. In: DOXA: Cuadernos de Filosofía del Derecho.cit. p. 120. 
adequadamente; e, finalmente, como deve ser feito com um critério que se pretenda objetivo, deve-se dispor de algum mecanismo para controlar se foi manejado ou não como é devido pelo órgão responsável por sua aplicação ${ }^{43}$.

De fato, se manejado pelo juiz profissional que irá, ao final, motivar sua decisão, o standard objetivo estará mais apto a cumprir sua finalidade, inclusive permitindo que qualquer pessoa possa analisar a fundamentação da decisão e exercer um controle, uma fiscalização da atividade valorativa. Isso, de fato, poderia reduzir a subjetividade que acomete a busca da verdade e resulta em erros de valoração.

No entanto é certo que a situação fica mais complicada no júri, tendo em vista os veredictos comumente não motivados ${ }^{44}$. Interessante sobre esse ponto citar o exemplo da Espanha, em que a Lei Orgânica do Tribunal do Júri (LOTJ) procurou corrigir essa subjetividade por meio, não somente da exigência de que os jurados apresentem uma sucinta explicação dos motivos que levaram à decisão, mas também pela forma como o questionário é elaborado, fazendo com que o júri se veja levado a analisar cada fato alegado pela acusação e cada fato alegado pela defesa para, através das provas produzidas, julgar se consideram cada um deles provados ou não ${ }^{45}$.

Assim sendo, evidencia-se uma tendência do júri espanhol a levar o jurado a uma análise racional (visto que deve analisar cada fato) e sujeita a controle, por meio da sucinta explicação que deve estar presente na ata da votação. Se aliado à perspectiva da construção de um standard objetivo, à luz das proposições de Laudan, tal sistema levaria a padrões bem mais aceitáveis de racionalidade da decisão. Modelos como esse devem servir para inspirar reformas nas instituições de júri, que não mais devem subsistir guiados unicamente por valores extra-epistêmicos.

43 SALAVERRÍA, Juan Igartua. "Prolongaciones a partir de Laudan". In: DOXA: Cuadernos de Filosofía del Derecho.cit. p. 146.

44 Quanto a essa questão em particular, já está sendo delineada uma mudança de perspectiva, tendo sido inclusive objeto de análise pelo Tribunal Europeu de Direitos Humanos no caso Taxquet v. Bélgica, 2010. O que segue da análise feita pela Corte é que a Convenção Europeia de Direitos Humanos não exige que os jurados fundamentem as decisões. No entanto, para que as exigências do fair trial sejam satisfeitas, o acusado e também o público devem ser aptos a entender o veredicto dado, o que constitui uma garantia vital contra arbitrariedades. A Corte também lembrou que decisões motivadas servem para o propósito de demonstrar às partes que elas foram ouvidas e contribuem para uma maior aceitação da decisão. Além do mais, obrigam os juízes a basear suas razões em argumentos objetivos e preservarem os direitos de defesa. No caso de tribunais do júri, as funções processuais devem ser acomodadas, uma vez que os jurados não fundamentam suas decisões. Essas garantias podem estar inseridas, por exemplo, nas instruções para os jurados dadas pelo juiz-presidente e nas questões postas aos jurados, desde que sejam aptas a estabelecer uma racionalidade sobre a qual o veredicto se baseará, compensando suficientemente a falta de razões para as respostas dos jurados.

45 Artigos 52 e 61 da LOTJ. Disponível na internet: http://noticias.juridicas.com/base_datos/ Penal/lo5-1995.html\#c4. [Acesso em: 29/10/2014]. 
Os standards probatórios como métrica da verdade: em busca de parâmetros objetivos

\section{Considerações finais}

O presente trabalho procurou situar a verdade como importante valor a ser observado no processo, como pressuposto da justiça das decisões, onde importante se fez a análise do que se compreende como conceito de verdade. Nesse contexto, a concepção de verdade como correspondência parece ser a mais adequada para nortear a atividade probatória e a valoração pelo juiz, associada à função demonstrativa da prova.

Essas conclusões são importantes para assemelhar a atividade de busca da verdade no processo àquela realizadaem diversas áreas de conhecimento, como nas ciências experimentais, na reconstrução dos fatos históricos, na matemática, dentre outras.

É certo que o processo comporta uma série de limitações a essa atividade de reconstrução dos fatos, muitas delas não orientadas à finalidade epistêmica, mas fundadas em valores igualmente importantes e que merecem semelhante cuidado. Algumas dessas limitações -que poderão representar uma maior dificuldade na descoberta da verdade- se justificam no processo para salvaguardar outra ordem de valores e, por tal motivo, deverão ser mantidos para evitar que o processo represente uma violação indevida a direitos igualmente relevantes. Conforme salienta Greco, "a verdade não pode ser obtida a qualquer preço, pois o Estado de Direito, assentado na dignidade de todos os seres humanos e na eficácia concreta dos seus direitos fundamentais, não pode admitir que a tutela dos direitos de uns se faça com o sacrifício de um núcleo intangível dos próprios direitos fundamentais de outros" ${ }^{\prime 46}$.

No entanto, existem algumas normas que limitam a atividade probatória -e por isso consideradas contra-epistêmicas- que não se respaldam em valores relevantes e, por tal motivo, devem ser suprimidas ou adaptadas para que o processo possa se orientar para a descoberta da verdade.

Em relação aos standards probatórios, muito pode ser feito nesse sentido. Acima foi dado destaque para o procedimento do júri tomando-se por base o modelo anglo -americano. Os jurados são orientados a decidir conforme os standards, no entanto, por sua formulação subjetiva e vaga, não há propriamente uma preocupação em assegurar a racionalidade no momento da formação do convencimento, o que é agravado pela falta de motivação dos veredictos e compromete a busca da verdade como correspondência. Assim, sugeriu-se uma análise do modelo espanhol de quesitação, que acaba por vincular os jurados à verificação dos fatos e provas exigindo, ao fim, uma sucinta explicação do veredicto, o que pode servir como inspiração de reformas para os Estados que contemplam o júri em seus sistemas de justiça.

46 GRECO. Op. cit. p. 120. 
Marcella Alves Mascarenhas Nardelli y Fabiana Alves Mascarenhas

De todo modo, o que deve ficar claro é a necessidade de se reavaliar o procedimento probatório como um todo e, paralelamente aos outros interesses relevantes, direcioná-lo também à finalidade epistêmica. Desta forma, a verdade poderá deixar de ser considerada um valor inalcançável e passar a ser um ponto de referência a orientar a atividade dos atores processuais.

\section{Referências}

ABELLÁN, Marina Gascón. "Sobre la posibilidad de formular estándares de prueba objetivos". In: DOXA: Cuadernos de Filosofía del Derecho. nº 28, 2005.

BELTRÁN, Jordi Ferrer. La valoración racional de la prueba. Madrid: Marcial Pons, 2007.

DAMASKA, Mirjan. "Truth in adjudication”. In: Hastings Law Journal, 1998. risk. $\mathrm{n}^{\circ} 02,2003$.

"Epistemology and legal regulation of proof". In: Law, probability and

GARAPON, Antoine; PAPAPOULOS, Ioannis. Julgar nos Estados Unidos e na França. Cultura Jurídica Francesa e Common Law em uma Perspectiva Comparada. Trad. de Regina Vasconcelos. Rio de Janeiro: Lumen Juris, 2008.

GRECO, Leonardo. Instituições de Processo Civil. Vol. II. Rio de Janeiro: Forense, 2011.

"A Verdade no Estado Democrático de Direito". In: Doutrinas Essenciais de Direito Civil. vol. 1. São Paulo: Revista dos Tribunais, 2010.

"A prova no processo civil: do Código de 1973 ao novo Código Civil". In:

. Estudos de Direito Processual. Campos dos Goytacazes: Faculdade de Direito de Campos, 2005.

"Garantias Fundamentais do Processo: O Processo Justo". In: Estudos de Direito Processual. Campos dos Goytacazes: Faculdade de Direito de Campos, 2005.

LAUDAN, Larry. Verdad, error y proceso penal: un ensayo sobre epistemología jurídica. Madrid: Marcial Pons, 2013.

"Por qué un estándar de prueba subjetivo y ambiguo no es un estándar". In: Doxa: Cuadernos de Filosofía del Derecho, n 28, 2005.

KIELMANOVICH, Jorge. Procesos de Familia. Buenos Aires: Abeledo - Perrot. 1998.

MICHELI, Gian Antonio; TARUFFO, Michele. A prova. Tradução Teresa Celina de Arruda Alvim. Revista de Processo. São Paulo. n.16. out/dez 1979.

MITTERMAIER, C. J. A. Tratado de la prueba en materia criminal. Madrid: Imprenta de la Revista de Legislación, 1857.

MORELLO, Augusto. La prueba: tendencias modernas. 2. ed. La Plata: Libreria Editora Platense. 1998. 
Os standards probatórios como métrica da verdade: em busca de parâmetros objetivos

OLIVEIRA, Carlos Alberto Álvaro de. Do formalismo no processo civil. 2. ed. São Paulo: Saraiva. 2003.

SALAVERRÍA, Juan Igartua. "Prolongaciones a partir de Laudan". In: DOXA: Cuadernos de Filosofía del Derecho, n 28, 2005.

TARUFFO, Michele. "La Verdad como Valor Social y Jurídico". In: __. Proceso y Decisión: Lecciones Mexicanas de Derecho Procesal. Madrid: Marcial Pons, 2012.

. La Prueba de los Hechos. Trad. Jordi Ferrer Beltrán. Madrid: Trotta, 2005.

. Uma simples verdade: o juiz e a construção dos fatos. Trad. Vitor de Paula Ramos. São Paulo: Marcial Pons, 2012.

"Consideraciones sobre Prueba y Verdad". In: ___. Sobre las fronteras: Escritos sobre la justicia civil. Trad. Beatriz Quintero. Bogotá: Editorial Temis, 2006.

. La Prueba. Madrid: Marcial Pons, 2008.

"Considerazioni su prova e motivazione". In: Revista de Processo. Ano 32, $\mathrm{n}^{\circ} 151$, setembro de 2007.

. La motivación de la sentencia civil. Trad. de Lorenzo Córdova Vianello. México: Tribunal Electoral del Poder Judicial de la Federación, 2006.

"La dimensión epistémica del proceso". In: Proceso y decisión: lecciones mexicanas de Derecho Procesal. Madrid: Marcial Pons, 2012.

"Tres observaciones sobre 'Por qué un estándar de prueba subjetivo y ambiguo no es un estándar', de Larry Laudan”. In: DOXA: Cuadernos de Filosofía del Derecho, n 28, 2005. 